\title{
EFFICACY AND SAFETY OF SPINAL ANAESTHESIA IN PAEDIATRIC AGE GROUP BETWEEN 3 TO 14 YEARS FOR INFRAUMBLICUS SURGERY
}

\author{
Gautam $S^{1}$, Acharya $S^{1}$, Bajracharya $G^{1}$, Hyoju $S^{2}$
}

${ }^{1}$ Department of Anaesthesia, Nepal Medical College, Attarkhel, Gokarneshwor-8, ${ }^{2}$ Department of Anaesthesia, Police Hospital, Maharajgunj, Kathmandu, Nepal.

\begin{abstract}
Spinal anaesthesia (SA) in paediatric patients was first introduced by August Bier in 1899. But this technique did not gain wide spread popularity in paediatric age group because of the introduction of various muscle relaxants and inhalational agents for general anaesthesia. SA in paediatric population has been gradually reintroduced as an alternate to general anaesthesia. The study was performed at the Nepal Medical College Teaching Hospital to evaluate the efficacy and safety of SA in paediatric age groups, compare the change in vital parameters such as heart rate, blood pressure and oxygen saturation during preoperative and intraoperative period, the complications of SA and time of demand for first rescue analgesia in postoperative ward. Sixty-seven patients aged between 3 years to 14 years of ASA I and ASA II were selected after screening for anaesthesia fitness. The duration of surgery ranged from $49.85 \pm 11.55$ to $56.30 \pm 9.68$ minutes and the blood loss was less than $10 \%$ of total blood volume, thus there was no need to transfuse during operation. The duration of analgesia ranged between $107.69 \pm 7.25$ to $115.00 \pm 7.07$ minutes in different age groups. Sixty patients (89.55\%) achieved Bromage Scale Score (BSS) 3 with interpretation of complete block; seven patients (10.45 \%) achieved Bromage Scale Score 2 (partial block) and were operated after supplimental intravenous sedation. None of the patients needed conversion to general anaesthesia. Successful CSF drain with placement of spinal needle in 1st attempt was achieved among 55 patients (82.1\%) and in 2nd attempt among 12 patients (17.9\%). No unsuccessful attempt was recorded. SA in children appears to be a relatively safe technique with few complications and may be considered as an alternative for general anaesthesia. It is cost effective in comparison to general anaesthesia as the drugs and equipment required are less and cheaper and the length of hospital stay is usually shorter.
\end{abstract}

\section{KEYWORDS}

Paediatric spinal anaesthesia, efficacy and safety, analgesia time, complication

\section{CORRESPONDING AUTHOR}

Dr. Shailendra Nath Gautam

Assistant Professor,

Department of Anaesthesiology,

Nepal Medical College and Teaching Hospital, Attarkhel, Gokarneshwor-8, Kathmandu, Nepal

Email: shailendragautam@hotmail.com 


\section{INTRODUCTION}

Spinal anaesthesia (SA) in paediatric patients was first introduced by August Bier in 1899. But it was not well established in the medical field as anesthesiologists were reluctant to use in paediatric patients. It was first used by Bainbridge in 1909 to repair strangulated hernia in a neonate. ${ }^{1}$ Since then SA was known to be in practice for several years with a series of publications. ${ }^{2}$ After some years of practice it was hardly used due to the introduction of various muscle relaxants and inhalational agents. ${ }^{3}$ In 1980 `s it was reintroduced as an alternate to general anaesthesia, especially in high risk preterm infants. ${ }^{4}$

In recent year SA in used in infants and children for different types of surgery of lower part of body. It can be used as a sole technique with or without sedation or in conjunction with general anaesthesia in complex surgery. ${ }^{5}$ Neuraxial anaesthesia continues to gain popularity because of rapid onset and profound uniformly distributed sensory and motor block with high success rate. ${ }^{6,7}$

Abajjan et al ${ }^{8}$ in 1984 stated that in the modern era of anaesthesia practice, SA has been successfully reintroduced in the paediatric age group due to a higher degree of cardiovascular and respiratory stability. In several studies, SA in paediatric patients has shown a decreased incidence of hypotension, hypoxia, bradycardia and postoperative apnoea in comparison to general anaesthesia. ${ }^{6,9}$

The efficacy and safety of SA in paediatric age group has encouraged its acceptance as an alternative to general anaesthesia, and to avoid the risks related to general anaesthesia such as unpredicted difficult airway, cardiovascular collapse, malignant hyperthermia and the procedure can be perform in low resources setting. ${ }^{10}$ The SA produces uniform sensory block with rapid onset and good muscle relaxation so it can be used as sole procedure and increasingly it has been used in combination with general anaesthesia in recent year in spite of that SA remains underutilized in children relative to general anaesthesia.

This study was carried out to evaluate the efficacy and safety of SA in paediatric age group and compare the vital parameter i.e. Heart rate (HR), Noninvasive blood pressure (NIBP), Oxygen saturation $\left(\mathrm{SPO}_{2}\right)$ during preoperative, intraoperative period, assess the complications of SA and analyze the first rescue analgesia demand time in post-operative ward.

\section{MATERIALS AND METHODS}

The study was performed from 2018 March to 2019 Feb at the NMCTH after getting clearance from institutional ethical committee.

The patients included in the study were admitted through the respective department after proper counseling about the anaesthesia and surgical procedure to be done. For the study, total of 67 paediatric patients aged between 3 to 14 years of American society of Anaesthesiologist (ASA I and ASA II) were selected for pre-anaesthesia checkup and advised to keep nil per orally (NPO) for 4-6 hours depending upon the type of last food child has taken. Patients with coagulation disorder, infection at local site, sepsis, abnormal vertebral anatomy and history of low birth weight were excluded in this study. In the next morning patients were transferred to the operation theater where intravenous (IV) access was secured and premedication was done with IV atropine $0.01 \mathrm{mg} / \mathrm{kg}$ and ketamine $2 \mathrm{mg} / \mathrm{kg}$ body weight. All necessary patient monitors (ECG, NIBP, $\mathrm{SPO}_{2}$ ) was attached and the patient was placed in lateral decubitus position with supplemental oxygen through nasal prong or face mask. Baseline vitals were recorded and lumbo-sacral region was prepared and draped with sterile towel. L3-L4 or L4L5 space was identified and lumbar puncture was done with 25G Quincke spinal needle. After the free flow of cerebro-spinal fluid (CSF), calculated dose of $0.5 \%$ bupivacaine heavy was injected according to the weight of child i.e $0.5 \mathrm{mg} / \mathrm{kg}$ for children $<5$ kilogram, $0.4 \mathrm{mg} / \mathrm{kg}$ (for $5-15 \mathrm{~kg}$ ), $0.3 \mathrm{mg} / \mathrm{kg}$ (for $>15 \mathrm{~kg}$ ) in subarachnoid space ${ }^{2,11,12}$ and $0.05-0.1 \mathrm{ml} 0.5 \%$ bupivacaine heavy was added to compensate for dead space of the needle. ${ }^{7}$ Bupivacaine is an amide class of local anaesthetic with moderately rapid onset and long duration of action which is highly protein bound and metabolized in liver. ${ }^{9}$

After injecting $0.5 \%$ bupivacaine heavy the spinal needle was withdrawn and puncture site was covered with sterile gauge. Then the patient was kept in the desired position according to surgical procedure ${ }^{13}$. The data recorded included age, sex, weight, type of surgery, duration of surgery along with duration of analgesia including any unsuccessful insertion of spinal needle and complications. The efficacy of sensory block was assessed with response to pin prick and the motor block was assessed as child's inability to move lower limb assuming that low dose of ketamine used as sedative did not mask the perception of sensory and motor response. In awake children, the assessment of block was done by pinprick, finger pinch, and ice whereas in sedated children, block was assessed by inability to move the extremity after emergence which was a good evidence of successful block. Motor block was assessed by BSS. After establishment of block, surgery was allowed to be performed and the patient was observed for any change in ECG, NIBP, $\mathrm{SPO}_{2}$ or any discomfort.

For the maintenance and replacement fluid Ringer lactate was used. On completion of surgery patient was observed for full recovery then shifted to postoperative care unit for further monitoring and on next day patient was shifted to respective ward. The data were collected and statistical analysis was done using SPSS version 16. 


\begin{tabular}{|lccc|}
\multicolumn{4}{c|}{ Table 1: Demographic data } \\
Demographic & 3-6 years, $\mathbf{n}(\%)$ & 7-10 years, $\mathbf{n}(\%)$ & $\mathbf{1 1 - 1 4}$ years, $\mathbf{n}(\%)$ \\
Number of pt & $10(14.93)$ & $13(19.40)$ & $44(65.67)$ \\
Age (Mean \pm SD yrs) & $5.3 \pm 0.95$ & $8.61 \pm 1.56$ & $12.57 \pm 0.93$ \\
Male & $6(14.29)$ & $10(23.81)$ & $26(61.90)$ \\
Female & $4(13.79)$ & $7(24.14)$ & $18(62.07)$ \\
Weight (Mean \pm SD kg) & $34.1 \pm 12.85$ & $31.61 \pm 10.36$ & $34.52 \pm 10.78$ \\
ASA I & $10(14.93)$ & $13(19.40)$ & $44(65.67)$ \\
\hline
\end{tabular}

Table 2: Types of surgery

\begin{tabular}{|lccc|} 
Operations & 3-6 years, $\mathbf{n}(\%)$ & $\mathbf{7 - 1 0}$ years, $\mathbf{n}(\%)$ & $\mathbf{1 1 - 1 4}$ years, $\mathbf{n}(\%)$ \\
Appendectomy & $4(40.00)$ & $1(84.62)$ & $27(61.36)$ \\
Phimosis/Herniotomy & $5(50.00)$ & $1(7.69)$ & $11(25.00)$ \\
Orthopaedic surgery & $1(10.00)$ & 0 & $2(4.55)$ \\
Others & 0 & $1(7.69)$ & $4(9.09)$ \\
\hline
\end{tabular}

Sixty-seven patients of different age group, sex and weight of ASA I and II categories were included in this study, out of which 10 patients were in age group 3-6 years (14.93\%), 13 patients were in age group 7-10 years $(19.40 \%)$ and 44 patients were in age group 11-14 years (65.67\%).

The mean age of children in different groups was $5.3 \pm 0.95,8.61 \pm 1.56,12.57 \pm 0.93$ years and mean weight was $34.1 \pm 12.85,31.61 \pm 10.36,34.52 \pm 10.78$ $\mathrm{kg}$ respectively. A majority of the children (65.67\%). were in age group 11-14 years (Table 1).

Maximum number of operation performed were appendectomy $32(47.76 \%)$, phimosis and hernia repair 17 (25\%), orthopaedic $3(4.47 \%)$ and others 5

\begin{tabular}{|lcc|}
\hline \multicolumn{3}{|c|}{ Table 3: No of attempts to drain CSF } \\
\hline Number attempts & $\mathbf{n}$ & $\%$ \\
$1^{\text {st }}$ & 55 & 82.1 \\
$2^{\text {nd }}$ & 12 & 17.9 \\
Total & $\mathbf{6 7}$ & $\mathbf{1 0 0}$ \\
\hline
\end{tabular}

(7.46\%) of ASA I and no patients were of ASA II in all age groups (Table 2).

The successful CSF drain with placements of spinal needle in $1^{\text {st }}$ attempt in 55 patients $(82.1 \%)$ and in $2^{\text {nd }}$ attempt in 12 patients $(17.9 \%)$. No unsuccessful attempt was recorded (Table 3 ).

\begin{tabular}{|c|c|c|c|c|c|c|c|c|}
\hline \multirow{2}{*}{$\begin{array}{l}\text { Event } \\
\text { Time }\end{array}$} & \multicolumn{2}{|c|}{ Heart Rate/min } & \multicolumn{2}{|c|}{ SBP $\mathrm{mm}$ of $\mathrm{Hg}$} & \multicolumn{2}{|c|}{ DBP $\mathrm{mm}$ of $\mathrm{Hg}$} & \multicolumn{2}{|c|}{$\mathrm{SpO}_{2} \%$} \\
\hline & Mean \pm SD & $\begin{array}{l}\text { Min- } \\
\text { Max }\end{array}$ & Mean \pm SD & $\begin{array}{l}\text { Min- } \\
\text { Max }\end{array}$ & Mean \pm SD & $\begin{array}{l}\text { Min- } \\
\text { Max }\end{array}$ & Mean \pm SD & $\begin{array}{l}\text { Min- } \\
\operatorname{Max}\end{array}$ \\
\hline Pre SAB & $99.91 \pm 8.88$ & $81-110$ & $108.3 \pm 6.56$ & $100-120$ & $70.57 \pm 4.78$ & $60-80$ & $98.54 \pm 0.5$ & $98-99$ \\
\hline Post SAB & $99.24 \pm 9.76$ & $75-110$ & $108.81 \pm 3.48$ & $100-118$ & $69.28 \pm 2.78$ & $60-78$ & $98.76 \pm 0.43$ & $98-99$ \\
\hline Intra op 0 min & $101.45 \pm 7.23$ & $85-110$ & $108.87 \pm 1.49$ & $106-110$ & $69.82 \pm 3.79$ & $66-90$ & $98 \pm 1.67$ & $92-99$ \\
\hline Intra op $5 \mathrm{~min}$ & $100.37 \pm 6.94$ & $90-108$ & $109.79 \pm 2.61$ & $106-118$ & $69.94 \pm 1.63$ & $66-74$ & $98.43 \pm 0.5$ & $98-99$ \\
\hline Intra op $10 \mathrm{~min}$ & $100.21 \pm 8.86$ & $88-116$ & $110.54 \pm 4.3$ & $104-120$ & $70.69 \pm 2.62$ & $68-80$ & $98.22 \pm 0.95$ & $96-99$ \\
\hline Intra op $15 \mathrm{~min}$ & $101.76 \pm 7.56$ & $88-110$ & $109.4 \pm 2.74$ & $106-118$ & $69.91 \pm 1.01$ & $68-72$ & $98.34 \pm 0.48$ & $98-99$ \\
\hline Intra op $30 \mathrm{~min}$ & $100.01 \pm 8.05$ & $88-110$ & $109.58 \pm 3.88$ & $104-120$ & $69.34 \pm 3.03$ & $60-74$ & $98.13 \pm 1.14$ & $96-100$ \\
\hline Intra op $45 \mathrm{~min}$ & $101.03 \pm 7.95$ & $88-112$ & $110.03 \pm 3.56$ & $106-120$ & $69.58 \pm 2.9$ & $60-74$ & $98.39 \pm 0.7$ & $97-99$ \\
\hline Intra op $60 \mathrm{~min}$ & $102.88 \pm 8.52$ & $88-112$ & $110.54 \pm 3.47$ & $106-120$ & $70.48 \pm 1.31$ & $70-74$ & $96.87 \pm 8.06$ & $94-99$ \\
\hline
\end{tabular}


The mean heart rate during pre-Sub Arachnoid Block (SAB) was $99.91 \pm 8.88$ per min and $102.88 \pm 8.52$ per min in intraoperative period after $60 \mathrm{~min}$. This shows increase in heart rate. The mean preSAB mean systolic blood pressure (SBP) was $108.3 \pm 6.56$ $\mathrm{mm}$ of $\mathrm{Hg}$ and intraoperative mean SBP after 60 min was $110.54 \pm 3.47 \mathrm{~mm}$ of $\mathrm{Hg}$ and preSAB mean diastolic blood pressure (DBP) $70.57 \pm 4.78$ and intraoperative mean DBP was $70.48 \pm 1.31 \mathrm{~mm}$ of Hg 60 min after intraoperative, which shows there was no change or negligible change in mean $\mathrm{HR}$ and $\mathrm{BP}$. Whereas $\mathrm{SPO}_{2}$ change during preSAB and $60 \mathrm{~min}$ after intraoperative shows $98.54 \pm 0.5 \%$ and 96.87 $\pm 8.06 \%$.This shows there was negligible change in Mean $\mathrm{SPO}_{2}$ (Table 4).

The time duration of surgery range from 49.85 \pm 11.55 to $56.30 \pm 9.68$ minutes and the blood loss was less than $10 \%$ of total blood volume, thus no need to transfuse during operation. The duration of analgesia ranged between $107.69 \pm 7.25$ to $115.00 \pm$ 7.07 minutes in different age groups (Table 5).

\section{Table 5: Duration of surgery and analgesia}

\begin{tabular}{|lcc|}
$\begin{array}{l}\text { Age Group } \\
\text { (years) }\end{array}$ & $\begin{array}{c}\text { Surgical time } \\
\text { (min) }\end{array}$ & $\begin{array}{c}\text { Duration of } \\
\text { analgesia (min) }\end{array}$ \\
$3-6$ & $56.30 \pm 9.68$ & $115.00 \pm 7.07$ \\
$7-10$ & $49.85 \pm 11.55$ & $107.69 \pm 7.25$ \\
$11-14$ & $53.84 \pm 11.47$ & $112.09 \pm 8.45$ \\
\hline
\end{tabular}

Table 6: Percentage of effective block

\begin{tabular}{lccc|}
$\begin{array}{l}\text { Bromage scale } \\
\text { Descriptions }\end{array}$ & Score & $\mathbf{n}$ & $\%$ \\
$\begin{array}{l}\text { Free movement of leg, feet } \\
\text { raise extended legs. } \\
\text { Inability to raise extended }\end{array}$ & 0 & 0 & 0.00 \\
leg, but able to flexion knee & 1 & 0 & 0.00 \\
and feet. & & & \\
$\begin{array}{l}\text { Inability to raise extended } \\
\text { leg and move knees, able to } \\
\text { move feet. }\end{array}$ & 2 & 7 & 10.45 \\
$\begin{array}{l}\text { Inability to raise leg and } \\
\text { knees or feet (complete } \\
\text { motor block). }\end{array}$ & 3 & 60 & 89.55 \\
\hline
\end{tabular}

Total 60 patients (89.55\%) achieved BSS 3 with interpretation of complete block, seven patients (10.45\%) achieved BSS 2 with interpretation of partial block and operated under intravenous sedation and none of the patient had to be converted into general anaesthesia in view of failed spinal block (Table 6).
Among all the age groups postoperative hemodynamic status was normal and one patient (2.3\%) of age group 11-14 years had nausea and vomiting. Whereas one patient $(7.7 \%)$ of age group 7-10 years had intraoperative bradycardia. This was treated with injection atropine $0.01 / \mathrm{kg}$. No other significant complication was noted (Table 7).

\section{DISCUSSION}

SA is being used frequently in sub-diaphragmatic surgeries to relieve postoperative pain and to achieve sensory block with muscle relaxation and decrease stress response so the recovery is fast in paediatric population.

In our study we used atropine $0.01 \mathrm{mg} / \mathrm{kg}$ and ketamine $2 \mathrm{mg} / \mathrm{kg}$ intravenously as sedative with supplemental oxygen to prevent movement causing contamination of the sterile field for the smooth spinal procedure in children assuming low dose sedation with ketamine may not mask the failure of block. Various authors have evaluated the number of attempts of spinal puncture in children ranging from $51 \%$ to $100 \%$ with first attempt success rate. ${ }^{18,19}$ In our study all patients were comfortable during the procedure with achieving $1^{\text {st }}$ attempt lumbar puncture (LP) in 55 children $(82.1 \%)$ and 12 children $(17.9 \%)$ required $2^{\text {nd }}$ attempt, none of patient had more than two attempts, which showed the feasibility and efficacy of LP in the paediatric patients when adequately sedated. In a study done by Kochko et al ${ }^{15}$ among 505 newborn and infants, $69.95 \%$ patients have successful LP in $1^{\text {st }}$ attempt. Whereas, the study carried out by Emmett et al $2017^{16}$ showed $89 \%$ successful LP in $1^{\text {st }}$ attempt. In another study carried out by Blaise and Ray, ${ }^{17}$ failure of LP was reported in 4 out of 34 children (11.76\%) after $2^{\text {nd }}$ attempt leading to conversion into general anaesthesia. Hence, our study was similar as compared to other studies for the success rate of LP. The reason behind this may be due to adequate sedation with the ketamine. Ketamine is a suitable drug for sedation in the neonate and paediatric age groups because of its high therapeutic index and ability to produce dissociative anaesthesia with intact airway reflex during sedation which has been also reported in similar studies. ${ }^{2}$

In our study, the patients remained hemodynamically stable during intraoperative as well as postoperative period except brief increase in heart rate before performing procedure. This may be because of atropine and ketamine used during procedure and there was no change in blood pressure which may be because of adequate prehydration to all patients.

\begin{tabular}{|lcccc|}
\multicolumn{1}{c}{ Event } & T-6 years $(\mathbf{n}=\mathbf{1 0})$ & $\mathbf{7 - 1 0}$ years $\mathbf{( n = 1 3 )}$ & $\mathbf{1 1 - 1 4}$ years $(\mathbf{n = 4 4 )}$ & Total $(\mathbf{n}=\mathbf{6 7})$ \\
Nausea/Vomiting & 0 & 0 & $1(2.3 \%)$ & $1(1.49 \%)$ \\
Bradycardia & 0 & $1(7.7 \%)$ & 0 & $1(1.49 \%)$ \\
Convulsion & 0 & 0 & 0 & 0 \\
Hypotension & 0 & 0 & 0 & 0 \\
Total & $\mathbf{0}$ & $\mathbf{1 ( 7 . 7 \% )}$ & $\mathbf{1 ( ( 2 . 3 \% )}$ & $\mathbf{2 ( 2 . 9 9 \% )}$ \\
\hline
\end{tabular}


The cardiovascular changes related to SA are less common in children in comparison to adults. ${ }^{2,20}$ This cardiovascular stability is a major advantage of spinal anesthesia in children with little or no changes in heart rate and blood pressure. ${ }^{10,11,21,22}$ However, some authors have demonstrated this hemodynamic stability in children upto the age of 5 years while others suggest that it may be seen even among those aged 8 to 15 years. .,11,23,24 $^{5}$ This extraordinary hemodynamic stability is still not well defined but one theory suggests that the younger children (5-8 years) have a relatively immature sympathetic nervous system and smaller intravascular volume in lower extremities and splanchnic system, which limits the venous pooling. ${ }^{25}$ This immaturity of the sympathetic nervous system would make vasomotor tone less dependent on sympathetic nervous system and the smaller capacitance veins in lower extremities causes less blood flows in children., ${ }^{3,10,26,27}$

The shorter duration of SA is an important limiting factor for infants and younger children. For this reason the surgeries of one hour duration is recommended under spinal anaesthesia in paediatric patients. The duration of spinal anesthesia in paediatric surgeries can be prolonged with larger dose of spinal anaesthetic or addition of different adjuvants. ${ }^{2}$ It has been observed that the duration of long acting local anaesthetic agent like bupivacaine is only about 45 minutes in neonates and 75-90 minutes in children of 5 years. ${ }^{23}$

The study carried out by Blaise and Ray ${ }^{17}$ on older children reported a mean duration of analgesia 70 min while using $0.6 \mathrm{mg} / \mathrm{kg}$ hyperbaric bupivacaine. Whereas, in our study the duration of surgery was between $49.85 \pm 11.55$ to $56.30 \pm 9.68$ minutes with blood loss less than $10 \%$ of total blood volume, therefore there was no need to transfuse during operation. The duration of analgesia ranged between $107.69 \pm 7.25$ to $115.00 \pm 7.07$ minutes in different age groups.

In our study, 53 patients $(86.1 \%)$ achieved $\mathrm{T}_{10}$ thoracic vertebra blockade after 10 minutes and was considered as successful spinal block whereas in 14 patients $(13.9 \%)$ desired level of spinal block were not achieved and required sedation during the surgical procedure were considered as partial block, and the child who required conversion into the GA for surgery was considered as failed block. In our study there was no incidence of any failed bock. This was assessed by using the BSS.

The onset of block is faster in infant because of greater blood flow to the spinal cord as compared to the adult and less cardiovascular related complication in children than adult. SA has been found cost effective as compared to general anaesthesia because of few drugs and equipment required, as well as in terms of the length of the hospital stay. ${ }^{29}$

Regarding the vital stability in our study, mean arterial pressure was normal in 66 patients $(98.50 \%)$ during perioperative and intraoperative period as all patient received preload maintenance fluid, but one patient (1.49\%) had noted brief period of hypotension. This may be due to inadequate preload of maintenance fluid just before the SA. This was corrected with crystalloid infusion at the rate of $10 \mathrm{ml} / \mathrm{kg}$ within 10 minutes. All other parameters that is heart rate, oxygen saturation and respiratory rate (HR, $\mathrm{SPO}_{2}$, and $\mathrm{RR}$ ) during our study was within the normal limit, and did not show much difference in preSAB and $60 \mathrm{~min}$ after intraoperative period, which is similar to the study by Warner et al. ${ }^{5}$

In the initial postoperative period SA provides effective analgesia but it has shorter duration in children than adults because of rapid pharmacokinetics in children as compared to adult. Since short duration of action of SA is a major limitation in children, a variety of additives like adrenaline, morphine, fentanyl, neostigmine, clonidine have been tried to prolong the block. ${ }^{30}$ In our study most of the children required analgesia within the first hour after completion of the surgery.

Complications of SA in children are less than in adults. ${ }^{29}$ Several authors have reported relative cardiovascular stability even with the higher blockades upto T4 level. ${ }^{30}$ In our study one patient had bradycardia (1.49\%), and one had nausea and vomiting, which shows the acceptability of SA in paediatric age groups. Whereas the study carried out by the Blaise and Ray ${ }^{17}$ reported no episodes of hypotension/arrhythmia or vomiting and less common cardiovascular related complication during SA in children than adults because of immature sympathetic system. The study carried by Kachko et $a l^{15}$ reported bradycardia with oxygen desaturation in $1.8 \%$ of their study population.

In conclusion, we recommend spinal anesthesia alone or with sedation as an alternate to general anaesthesia among the paediatric patients especially in high risk cases. In due course of time, paediatric SA may be the preferred choice of anaesthesia in lower abdominal and lower extremity surgeries in children. However, further research work in the large group of patients should be considered for the reliability of SA among children.

\section{REFERENCES}

1. Fortuna A, Caudal anaethesia. A simple and safe technique in pediatric surgery. Brit J Anaesth 1967; 39: 165-70.

2. Verma D, Naithani U, Gokula C, Harsha. Spinal anesthesia in infants and children: A one year prospective audit. Anesth Essay Res 2014; 8, 3: 324-9.

3. John FB, David CM, John DW. The Practice of Anesthesiology. In: Morgan and Mikhail `s Clinical Anaesthesiology. ( $5^{\text {th }}$ ed.), editor. United States: Lange Medical Book 2013; 1-9.

4. Lopez T, Sanchez JC, Garzon, Muriel. Spinal anesthesia in pediatric patients. Minerva Anesthesiologica 2012; 78: 1, 78-87. 
5. Warner MA, Kunkel SWE, Offord KO. Atchison SRD, Awason B. The effects of age and operative site on duration of caudal analgesia in pediatric patients. Anesth Analg 1987; 66: 995-8.

6. Banjare M, Singh S A prospective study to evaluate the feasibility of spinal anaesthesia in neonates. Int'l J Med Res 2018; 3: 85-7.

7. Sharma T, Shah N, Patel J, Chhaya A and Upadhyaya R. Comparison of general anesthesia vs caudal epidural in pediatric infra umbilical surgeries. Int'l J Biomed Res 2015; 6: 35-9.

8. Abajjan JC, Mellish RW, Browne AF, Perkins FM et al. Spinal anesthesia for surgery in the high- risk infant. Anesth Analg 1984; 63: 359-62.

9. Pandey C, Mehta K, Patel K, Panchasara K. Pediatric regional anesthesia- A comparison between pediatric spinal and caudal anesthesia. NHL Med Sci 2014; 3: 72-6.

10. Dahmani S, Michelet D, Abback PS et al. Ketamine for perioperative pain management in children: a meta-analysis of published studies. Paediatr Anaesth 2011; 21: 636-52.

11. Lopez T, Sanchez JC, Garzon, Muriel. Spinal anesthesia in pediatric patients. Minerva Anesthesiologica 2012; 78: 78-87.

12. Kokki H, Tuovinen K, Hendolin H. Spinal anaesthesia for paediatric day case surgery: a double blind randomized parallel group prospective comparison $\mathrm{f}$ isobaric and hyperbaric bupivacaine. Brit J Anaesth 1998; 81: 502-6.

13. William JM, Stoddart PA. Williams SA, Wolf AR. Post-operative recovery after inguinal herniotomy in ex-premature infants: Comparison between Sevoflurane and Spinal anesthesia. Brit J Anaesth 2001; 86: 366-71.

14. Rochette A, Raux O, Troncin R, Dadure C, Verdier R, Capdevila X. Clonidine prolongs spinal anesthesia in newborns: A prospective dose ranging study. Anesth Analg 2004; 98: 56-9.

15. Kachko L, Simhi E, Tzeitlin E, Efrat R et al. Spinal anesthesia in neonates and infants - a single-center experience of 505 cases. Pediatr Anesthesia 2007; 17: 647-53.

16. Emmett EW, Brianne ZW, Daiel GD, Seth AA et al. Spinal anesthesia for pediatric urological surgery:Reducing the theoretic neurotoxic effects of general anesthesia. J Pediatr Urol 2017; 13: 396400 .
17. Blaise GA, Roy WL. Spinal anaesthesia for minor paediatric surgery. Canadian Anaesthetists Soc J 1986; 33: 227-30.

18. Webster A, McKishnic J, Kenyon C Spinal anesthesia for inguinal repair in high risk neonates. Can $J$ Anaesth 1991; 38: 281-6.

19. Rice JL, De Mars PD, Whalen TV et al. Duration of spinal anesthesia in infants less than over year of age. Reg Anesth 1994; 19: 325-9.

20. 20. Miqdady MI, Hayajneh WA, Abdelhadi R, Gilger MA. Ketamine and Medazolam sedation for pediatric gastrointestinal endoscopy in the Arab world. World J Gastroenterol 2011; 17: 3630-5.

21. Fernando1 C, Rifaya MI, Asantha WD, Chandrarathna R, Wijeratna AU. A comparison of three self-report pain scales in Sri Lankan children. Sri Lanka J Child Health 2017; 46: 23-8

22. Gingrich BK. Difficulties encountered in a comparative study of orally administered midazolam and Ketamine. Anesth 1994; 80: 1414-5.

23. Goyal R, Jirtjil K, Baj B, Singh S, Kumar S. Paediatric Spinal Anesthesia. Indian J Anaesth 2008; 52: 26470 .

24. Dohi S, Naito H, Takahashi T. Age related changes in blood pressure and duration of motor block in spinal anesthesia. Anesthesiology 1979; 50: 319-23.

25. Oberlander TF, Berde CB, Lam KE. Infants tolerate spinal anesthesia with minimal overall autonomic changes: analysis of heart rate variability in former premature infants undergoing hernia repair. Anesth Analg 1995; 80: 20-7.

26. Cote CJ. Preoperative preparation and premedication. Brit J Anaesth 1999; 83: 16-28.

27. Racheal T, Christophe D, Paediatric anesthesia. Internet Sci Publications 2015; 22-4.

28. Williams RK, Adams DC, Aladjem EV et al. The safety and efficacy of spinal anesthesia for surgery in infants: The Vermont Infant Spinal Registry. Anesth Analg 2006; 102: 67-71.

29. Troncin R, Christophe D. Paediatric spinal anaesthesia. In: principle of anaesthesia. Update in Anaesthesia 2009; 25: 22-4.

30. Gupta A, Saha U. Spinal anesthesia in children: A review. J Anaesthesiol Clin Pharmacol 2014; 30: 10-8 